\title{
Intravenous Thrombolytics for Ischemic Stroke
}

\author{
Andrew D. Barreto
}

Published online: 3 June 2011

(C) The American Society for Experimental NeuroTherapeutics, Inc. 2011

\begin{abstract}
For many decades, intravenous (IV) thrombolytics have been delivered to treat acute thrombosis. Although these medications were originally effective for coronary thrombosis, their mechanisms have proven beneficial for many other disease processes, including ischemic stroke. Treatment paradigms for acute ischemic stroke have largely followed those of cardiology. Specifically, the aim has been to recanalize the occluded artery and to restore perfusion to the brain that remains salvageable. To that end, rapid clot lysis was sought using thrombolytic medicines already proven effective in the coronary arteries. IV-thrombolysis for ischemic stroke began its widespread adoption in the late 1990s after the publication of the National Institute of Neurological Disorders and Stroke study. Since that time, other promising IV-thrombolytics have been developed and tested in human trials, but as of yet, none have been proven better than a placebo. Adjunctive treatments are also being evaluated. The challenge remains balancing reperfusion and salvaging brain tissue with the potential risks of brain hemorrhage.
\end{abstract}

Keywords Intravenous thrombolysis · Thrombolytics . Stroke $\cdot$ Treatment $\cdot$ Fibrinolytic $\cdot$ Ischemia

Electronic supplementary material The online version of this article (doi:10.1007/s13311-011-0049-x) contains supplementary material, which is available to authorized users.

A. D. Barreto $(\bowtie)$

Department of Neurology, Stroke Division, Neurosonology

Laboratory, University of Texas-Houston Medical School,

Houston, TX 77030, USA

e-mail: andrew.d.barreto@uth.tmc.edu

\section{Introduction}

Cerebrovascular disease represents an enormous burden of disease and disability to mankind. The World Health Organization estimates that 15 million people worldwide suffer a stroke each year. It is projected that in the year 2020, there will be a global loss of 61 million disability-adjusted life years and that number is up from 38 million in 1990. Disability-adjusted life years combine the years of potential life lost due to premature death with years of productive life lost due to disability [1]. Stroke is now the second leading cause of death for people older than 60 years of age [1]. In the United States, approximately 795,000 strokes occur annually. Fifteen to $30 \%$ of Americans are permanently disabled after their stroke and $20 \%$ require institutionalized care at 3 months after onset [2, 3]. Resultant stroke disability affects many different entities (i.e, spouse and children, extended family, communities, the healthcare system, and governmental budgets).

Because the vast majority of strokes are ischemic in etiology, the development of an effective treatment for clot dissolution was groundbreaking. Recombinant tissue plasminogen activator (r-tPA) was approved by the Food and Drug Administration (FDA) in the mid-1990s for the rapid lysis of ischemic stroke. The tissue plasminogen activator (tPA) resulted in a clinically important and statistically significant reduction in stroke disability and has continued to be the most important achievement in medical treatment of stroke. Other types of lytic drugs have either failed or clinical trials are presently ongoing.

\section{Physiology of Thrombolysis}

The term thrombolytic is usually synonymous with fibrinolytic. In the setting of ischemic stroke, this term 
specifically relates to degradation of fibrin, the tough netlike backbone of a clot that is blocking flow to a portion of the brain. The clot can form in-situ (i.e., a thrombus) or can travel from another source, such as a tight carotid stenosis or the heart (i.e., an embolus). From a clinical standpoint, a thrombolytic is a drug that is delivered for the purpose of recanalization of the occluded artery and reperfusion of ischemic, but still salvageable brain tissue (i.e., ischemic penumbra). If reperfusion is begun early enough and blood supply is renewed to the brain territory devoid of oxygen supply, the tissue can be salvaged and resultant damage can be lessened.

\section{Clot Formation}

Hemostasis or reaction to vascular injury is a complicated process that involves interactions between endothelium, platelets, the coagulation cascade, and ultimately fibrin formation.

The first phase in hemostasis involves platelet aggregation. After endothelial cell damage or tissue factor exposure, platelets adhere to the subendothelial surface and secrete growth factors and chemotactic agents. Because platelets do not adhere to normal endothelium, a disruption occurs first, which leads to adhesive protein activation (e.g., von Willebrand factor). Adhesion proteins bridge the subendothelial connective tissue and platelets. Platelets then begin aggregating rapidly after expressing the membrane receptor glycoprotein IIb/IIIa (GP2b3a). Platelet selfadhesion is mediated by fibrinogen, which helps form a high-affinity bond through the membrane receptor glycoprotein IIb/IIIa (GP2b3a) receptor. Through this process, platelets eventually form a mass of aggregated platelets [4].

In addition to forming an aggregated mass, the platelet surface serves to accelerate the clotting factors. The most important clotting factor is thrombin, as it occupies a central role in the process of clot formation. A major substrate of thrombin is fibrinogen, which forms fibrin monomers that are then polymerized and form the fibrin clot. Factor XIIIa increases the resistance of the clot to fibrinolysis by cross-linking individual fibrin monomers [5]. Thrombin also plays a role in protecting fibrin (from fibrinolysis) by activating thrombin-activated fibrinolytic inhibitor. The thrombin-activated fibrinolytic inhibitor impairs degradation of fibrin strands. Finally, further solidifying its central role in clot formation, thrombin is also the most potent activator of platelet aggregation.

Mechanisms of Thrombolysis

Most thrombolytic drugs that have been tested or are in use dissolve blood clots by activating plasminogen. The plasminogen, once cleaved, forms plasmin, which is the principle proteolytic enzyme capable of breaking crosslinks between fibrin molecules (Fig. 1). Because these cross-links between fibrin provide the structural integrity of the thrombus, dissolution can proceed. Therefore, it is not inaccurate to refer to these drugs as "plasminogen activators." Molecules that directly act on fibrin, such as plasmin or microplasmin are considered "direct fibrinolytic drugs." Henceforth, any drug that induces fibrinolysis (clot breakdown) will be referred to as a thrombolytic. This includes any drug that catalyzes the conversion of plasminogen to plasmin or acts directly on the fibrin as plasmin.

Other substances present in the blood inhibit the fibrinolytic pathway. The four principle inhibitors of this pathway include $\alpha 2$-anti-plasmin, $\alpha 2$-macroglobulin, plasminogen activator inhibitor, and thrombin (Fig. 1). Although these inhibitors play an important role, in the setting of acute ischemic stroke treatment using thrombolytics, they exist in insufficient concentrations to affect the desired fibrinolysis. An important theoretical difference between plasminogen activators and direct fibrinolytics is their differing susceptibility to these intrinsic inhibitors (see as follows).

\section{Thrombolytic Drugs}

Efficacy of thrombolytic drugs depends on a few important factors: 1) the age of the clot can reduce the efficacy of the thrombolytic, and older clots tend to have more fibrin crosslinking and are more resistant to thrombolytics [6];2) the specificity of the lytic for fibrin will determine its activity, and other determinants of efficacy include half-life and the presence of any neutralizing antibodies.

Thrombolytics can be divided into two different categories: 1) fibrin-specific thrombolytics and 2) nonfibrinspecific thrombolytics. Some examples of fibrin-specific

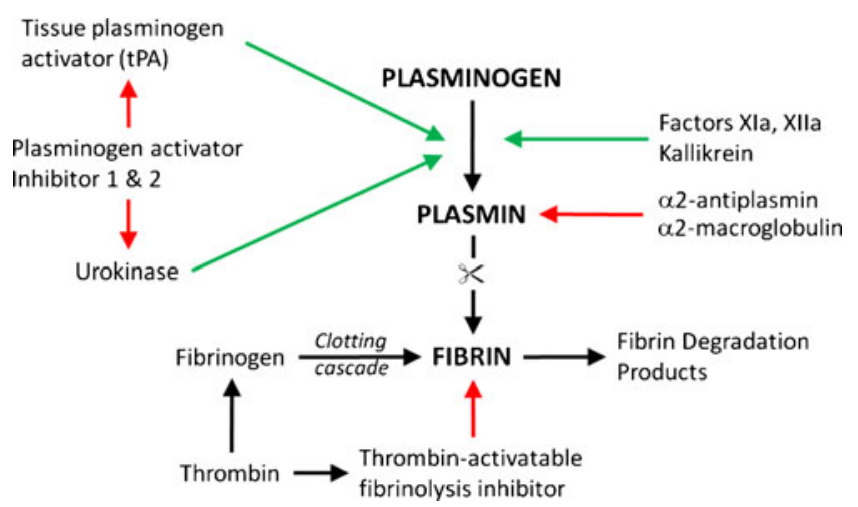

Fig. 1 Important endogenous substances and factors involved with clot formation. Green arrows indicate induction and red arrows inhibition 
drugs are: alteplase, reteplase, and tenecteplase. Nonfibrinspecific drugs include streptokinase or staphylokinase. Alternatively, lytics that convert plasminogen into plasmin can be described as direct versus indirect. Direct activators are the same as those previously listed for fibrin-specific drugs. Indirect activators of plasminogen include streptokinase, staphylokinase, and desmoteplase (vampire bat plasminogen activator). Direct activators are all serine proteases that cleave a single (arginine-valine) amino acid bond to yield plasmin. Indirect activators are not proteolytic, but rather form a complex with plasminogen which can then convert additional plasminogen to plasmin (for more details, see Table 1).

More recently, the testing of plasmin itself has been under development. The half-life of plasmin is very short; when administered by IV, plasmin is rapidly neutralized (within seconds) by $\alpha 2$-anti-plasmin, and it does not dissolve the thrombus or induce bleeding [7]. Thus, plasmin is better suited as a local agent (delivered at the site of thrombus in the setting of intra-arterial therapy).

\section{History of Thrombolytics}

The first thrombolytic activity was found by Tillet and Garner [8] to be produced by group A beta-hemolytic streptococci. In their 1933 publication, the authors isolated the strains of streptococci from 28 different patients who were suffering from illnesses, such as septicemia, tonsillitis, scarlet fever, and cellulitis. After culturing the bacteria, the culture was added to a human solid clot and the time to liquefy the thrombus was observed. The substance that Tillet and Garner [8] postulated was responsible for the clot dissolution was initially named fibrinolysin, but the name was later changed to streptokinase [9]. In the late 1940s, streptokinase was used therapeutically to treat bloody conditions, such as pleural exudates and hemothorax. Although Johnson and Tillet [10] were able to successfully lyse clots (in a rabbit model) using streptokinase, Fletcher et al. [11] were the first to deliver IV streptokinase to human patients suffering from acute myocardial infarction (AMI) in 1958.

Subsequent studies showed that streptokinase, by itself, is not a plasminogen activator, but it binds with free circulating plasminogen (or with plasmin) to form a complex that can convert additional plasminogen to plasmin. Streptokinase activity is not enhanced in the presence of fibrin. Because streptokinase is produced from streptococcal bacteria, it often causes febrile reactions and other allergic problems. Streptokinase can also cause hypotension that appears to be dose related. It is not advised to re-administer streptokinase within 6 months, because it is highly anti-genic and results in high levels of antibodies.

During the 1980s, through recombinant technology, multiple second and third generation lytics were developed and clinically tested. Probably the most well-known second generation agent is alteplase (recombinant tissue plasminogen activator [rt-PA]), which is manufactured using the human gene that has been inserted into a mammalian cell line (Chinese hamster ovary cells). Importantly, the product is identical to human tissue-type plasminogen activator. Due to its high fibrin specificity, the activity of alteplase is enhanced 400-fold when bound to fibrin [12]. Third generation thrombolytics had their chemical structure slightly altered to increase fibrin specificity and to increase half-life. Two of the most well-studied agents are tenecteplase and reteplase. An advantage of these medications is bolus dosing (no infusion necessary) due to their longer

Table 1 Thrombolytic drugs either approved or under past/current investigation for clinical use (myocardial infarction or stroke)

\begin{tabular}{|c|c|c|c|c|c|}
\hline Drug & Origin & $\begin{array}{l}\text { Direct Plasminogen } \\
\text { Activator }\end{array}$ & Fibrin Specific & $\begin{array}{l}\text { Half-life } \\
\text { (minutes) }\end{array}$ & Anti-genicity \\
\hline \multirow[t]{2}{*}{ Streptokinase } & \multirow[t]{2}{*}{ Streptococcus bacterium } & \multirow[t]{2}{*}{ No } & \multirow[t]{2}{*}{ No } & $\begin{array}{l}\text { Biphasic* } \\
\text { Short: } 18\end{array}$ & \multirow[t]{2}{*}{ Yes } \\
\hline & & & & Long: 89 & \\
\hline Urokinase & Embryonic kidney cells & Yes & No & $14-20$ & No \\
\hline${ }^{\dagger}$ Alteplase & Recombinant technology & Yes & Yes, but moderate & $3-6$ & No \\
\hline Pro-urokinase & Recombinant technology & Yes & Yes & $7-9$ & No \\
\hline${ }^{\dagger}$ Tenecteplase & Recombinant technology & Yes & Yes & $17-25$ & No \\
\hline Reteplase & Recombinant technology & Yes & Yes & $15-18$ & No \\
\hline${ }^{\dagger}$ Desmoteplase & Vampire bat saliva & Yes & Yes & 2.8-4 hours & Yes \\
\hline${ }^{\dagger}$ Plasmin & $\begin{array}{l}\text { Plasma-derived and recombinant } \\
\text { technology }\end{array}$ & No & Yes & $<1$ & unavailable \\
\hline
\end{tabular}

*Streptokinase (Streptase) [package insert], Ottawa, Ontario: CSL Behring Canada, Inc; 2007

${ }^{\dagger}$ Tested in past or ongoing intravenous (IV) ischemic stroke clinical trials 
half-life. A newer thrombolytic, desmoteplase is derived from vampire bat (Desmodus rotundus) saliva. As compared to rt-PA, desmoteplase has a much higher fibrin selectivity and a prolonged half-life of $4 \mathrm{~h}$ [13].

\section{Thrombolytics for Acute Myocardial Infarction}

Early experimentation with streptokinase in the setting of AMI was performed by Fletcher et al. [14] in their 1959 published case series, in which large doses of the drug were infused after myocardial infarction in 22 patients. A few patients developed mild hemorrhagic complications, but in comparison with other treatments (largely supportive at the time) they demonstrated promising lower mortality rates. In 1966, Schmutzler et al. [15] published 1 of the largest trials of that time, involving 558 patients. They reported an absolute decrease in mortality of $7.6 \%$ in streptokinase-treated patients compared with the control group. During the 1970s, many small, underpowered and nonrandomized trials were performed, which showed mixed results [16-18].

Two important clinical trials led to the eventual acceptance of IV thrombolysis for acute myocardial infarction:1) the European Cooperative Study Group for Streptokinase Treatment in Acute Myocardial Infarction [19] and 2) the Gruppo Italiano per la Sperimentazione della Streptochinasi nell'Infarto Miocardico (GISSI) trial [20]. Both studies were well designed and firmly established the efficacy of administering IV thrombolytic (streptokinsase) for acute myocardial infarction. Numerous trials followed that reinforced the same findings. Later in the late 1980 s and early 1990 s, efforts shifted to comparing newer thrombolytics with streptokinase.

Three major clinical trials compared rt-PA versus streptokinase: the Global Utilization of Streptokinase and Tissue Plasminogen Activator for Occluded Coronary Arteries (GUSTO) trial, the Third International Study of Infarct Survival (ISIS-3), and the GISSI-2 trial [21-23]. The Global Utilization of Streptokinase and Tissue Plasminogen Activator for Occluded Coronary Arteries (GUSTO) trial enrolled 41,021 patients to assess the effect of rt-PA, streptokinase, or a combination of both on survival (within $6 \mathrm{~h}$ of acute myocardial infarction onset). There was a benefit observed of rt-PA, but only when treatment was given early $(<4 \mathrm{~h})$. This benefit was especially true if the patient was $<75$ years old. The Third International Study of Infarct Survival (ISIS-3) trial enrolled 41,299 patients to streptokinase, rt-PA, or Eminase Manufacturer: Haupt Pharma Wulfing, Germany (anisoylated plasminogen-streptokinase activator complex). There were more allergic reactions and hypotension in streptokinase-treated patients, but no difference in mortality between groups. The GISSI-2 trial group studied 12,490 patients who received streptokinase ( \pm IV heparin) $v s$ rt-PA ( \pm IV heparin). No mortality differences were found in any of the four treatment groups; however, the incidence of major bleeding was greater in the streptokinase + heparin group. These 3 trials led to the overall preference for rt-PA, especially in the cases of: 1) history of receiving streptokinase (due to allergic reactions seen in 4 to $5 \%$ of cases, as well as antibodies, which possibly reduce efficacy; and 2) age $<75$ and onset within 4 hours.

Current recommendations state that in the setting of AMI of $<12$ hours duration and with ST-segment elevation, administration of fibrinolytic agent (streptokinase, alteplase, reteplase, or tenecteplase) is strongly recommended (grade 1A) [24]. Importantly, catheter-based therapies (e.g., percutaneous angioplasty and stenting) have been shown to be more effective thanIV thrombolysis alonein centers that have the capability.

\section{Thrombolysis for Cerebral Infarction: Early Development}

Initial studies of thrombolysis in humans began in the late 1950s, but with major limitations. First, studies at this time took place prior to the advent of computed tomography (CT) patients may have had hemorrhagic rather than ischemic strokes. Instead, despite its lack of reliability, a cerebrospinal evaluation was performed to help rule out hemorrhage. Next, the majority of these early trials lacked any form of cerebral vessel imaging to assess recanalization. Medications tested included plasmin, streptokinase, and urokinase. Because cerebrovascular dosing for streptokinase was extrapolated from the cardiac literature, the optimal dose was never determined. Finally, most studies were very small; patients were treated very late in the course of their ischemia; and few performed rigorous trial design with placebo groups and allocation blinding [25-28].

After the advent of CT in the early 1980s, case reports and small case series began to surface describing improved outcomes in urokinase- or streptokinase-treated patients $[29,30]$. However, robust testing of thrombolysis for stroke was thwarted by a 1980 National Institutes of Health consensus conference on thrombolytic therapy. The consensus statement expressed caution that due to increased risk of brain bleeding, thrombolysis for stroke should be avoided [31]. As a result, this recommendation made its way onto package labeling for urokinase and streptokinase.

Many crucial factors hampered the development of thrombolytics for ischemic stroke. First, the choice of thrombolytics was important. Some investigators continued to explore first generation drugs, such as streptokinase and urokinase. These older medications were less fibrin specific 
and led to unacceptable bleeding risks [32]. Second, combination anticoagulation or anti-platelet therapy was used. Both drug choice and concomitant drugs likely led to increased risk of symptomatic hemorrhage. Third, the time window for lysis was likely the most important factor for trial failure. Studies on primates demonstrated that approximately only 3- to 4-h of middle cerebral artery occlusion could be tolerated before irreversible damage occurred [33]. Despite this evidence, clinical trials were being designed with a 6-h window in which the majority of patients were receiving drugs in the 4- to 6-h time period. Finally, there was very little preclinical evaluation of the first generation thrombolytics. Despite these limitations, very important work was independently completed and somein collaboration by del Zoppo et al. [29], Zeumer [34], and Mori et al. [35] demonstrating the angiography evidence of arterial occlusion and response to fibrinolytic therapy in patients suffering large vessel occlusion. Authors del Zoppo et al. [36] treated 4 patients suffering from proximal intracranial occlusions with local infusion of streptokinase. Two patients were recanalized with marked clinical improvement, which did not occur in the absence of recanalization.

Although caution was recommended regarding the use of urokinase for ischemic stroke, the drug and its precursor, pro-urokinase, was still widely used, especially via the intra-arterial treatment approach. Pro-urokinase was tested using this local, catheter-based treatment in the Prolyse in Acute Cerebral Thromboembolism (PROACT) trials. Although, beyond the scope of the current review, endovascular treatment of pro-urokinase in 3- to 6-h stroke patients did result in greater rates of recanalization and improved clinical outcomes compared to a placebo, despite a cerebral hemorrhage rate of $10 \%$.

The molecular biological revolution in the early $1980 \mathrm{~s}$ led to the development of rt-PA. The most notable preclinical stroke evaluation of rt-PA using an embolic model was performed by Zivin et al. [37]. Using a rabbit model, small clots were injected into the animal's brain until a sufficient clot burden (weighed in milligrams) resulted in either an abnormal neurological examination or death. If rt-PA was injected, the absolute amount of the clot could be significantly increased before the examination changed or the animal died. Importantly, this was only true if the thrombolytic was started within 90 minutes of introducing the clots. Albeit small numbers, researchers did not encounter problems with brain hemorrhage in rtPA treated rabbits [38]. The opposite was true of streptokinase in this model, which demonstrated hemorrhage. The most important factor identified through this pre-clinical work was the 90-minute time window of efficacy. This 1.5 -h window would eventually lead to the study design that resulted in the first and only proven therapy for ischemic stroke.
At this point, a few but important factors led to the development of rt-PA for ischemic stroke in comparison with other thrombolytics. First, recombinant t-PA was identical to human tissue-type plasminogen activator and thus did not cause the anaphylactic-type reactions seen with streptokinase. Second, no antibodies were formed to rt-PA, so repeat dosing was feasible. Third, the most feared complication of thrombolysis intracranial hemorrhage seemed to be more common with other thrombolytics [32]. Finally, the pre-clinical work previously described using rt-PA demonstrated efficacy and safety.

\section{Early Safety and Dose-Finding Trials in Stroke}

Phase I dose-escalation clinical trials using alteplase (rt-PA) were carried out in the late 1980s in 2 parts: 1) $<90$ minutes from stroke onset $(n=74)$ and 2) 91 to 180 minutes $(n=20)$ $[39,40]$. Doses of alteplase ranged from 0.35 to $1.08 \mathrm{mg} / \mathrm{kg}$. Only 1 intracranial hematoma occurred among 64 patients (1.5\%) who received $\leq 0.85 \mathrm{mg} / \mathrm{kg}$ and none had other major hemorrhagic complications. Higher doses $(\geq 0.95 \mathrm{mg} / \mathrm{kg})$ were statistically associated with symptomatic intracranial bleeding. Most importantly, from a public health standpoint, the investigators demonstrated that stroke patients could be evaluated neurologically, receive a head CT scan, and be treated with IV t-PA within 90 minutes of symptom onset. Furthermore, results of these 2 phase I studies led to the eventual $0.9 \mathrm{mg} / \mathrm{kg}$ alteplase dose that is currently being used. Other studies that took place at approximately the same time generated similar results [3, 41]. Authors del Zoppo et al. [42] contributed important IV t-PA doserate escalation information in 139 patients who had recanalization monitored by a conventional angiogram. Their findings were among the first to describe differential efficacy of t-PA according to clot location (i.e., lower rates of recanalization in terminal internal carotid artery occlusions).

\section{Review of Phase 3 Efficacy Trials}

Three major phase III clinical trials of alteplase were conducted in the 1990s: 1) European Cooperative Acute Stroke Study (ECASS), 2) ECASS-II, and 3) the National Institute of Neurological Disorder and Stroke (NINDS) rtPA Stroke trial. The ECASS randomized 620 patients to placebo $v s 1.1 \mathrm{mg} / \mathrm{kg}$ alteplase within $6 \mathrm{~h}$ of symptom onset [43]. More than $80 \%$ of the patients were enrolled within the 3- to 6-h window, and the study did not reveal a significant difference between groups. However, post-hoc analysis revealed that if protocol violations were removed, then the analysis of the target-population did reveal a treatment effect of t-PA. 
The NINDS rt-PA study randomized patients with a placebo vs $0.9 \mathrm{mg} / \mathrm{kg}$ of alteplase within $3 \mathrm{~h}$ of symptom onset [44]. Half the patients were treated within 90 minutes of onset. The study was conducted in two parts. Part 1 was a phase 2 b study of 291 patients having a primary endpoint of a 4-point improvement on the National Institutes of Health Stroke Scale (NIHSS) at 24-h and was not positive, although it would have been positive if any other cutoff of NIHSS reduction was used by greater than 4 points. The secondary endpoint of a 3-month outcome was positive and generated part 2, a phase 3 study of 333 patients using the same inclusion and exclusion criteria as part 1 (Table 2), but used as its primary outcome a "consistent and persuasive difference" at 3 months. This was measured using a global statistic comprised of complete recovery on 4 different outcome measures (NIHSS, Barthel Index, modified Rankin scale and the Glasgow outcome scale). Despite greater rates of symptomatic intracerebral hemorrhage (ICH) $(6.4 \%$ vs $0.6 \%)$, alteplase-treated patients had a $13 \%$ absolute increase in the proportion of patients with no disability at 3 months. There were no differences between groups in regard to mortality. Several important substudies or secondary analyses confirmed reperfusion with t-PA [45], which showed that the positive results were generalizable across all common clinical variables, including stroke subtype, severity, and patient age [46]. The only predictors of hemorrhage were stroke severity and inadequate blood pressure control [47] with results that persisted at 1 year [48], and most importantly that the benefit was best seen if patients were treated within the first $2 \mathrm{~h}$ after onset [49]. Using the dichotomous outcome, the number needed to treat was 8 and the number needed to harm (causing a symptomatic hemorrhage) was 17. More recently, Saver et al. [50] used a shift-analysis, which uses the entire modified Rankin scale to account for any clinical improvement across the $0-6$ point scale. Using this technique, the number needed to treat to benefit was 3 and to harm was 32 [50]. Results of the NINDS trials led to 1996 Food and Drug Administration approval of alteplase for acute ischemic stroke. Other licensing bodies followed the Food and Drug Administration with approval, in Canada in 1999 and in Europe in 2002. However, resistance to the use of t-PA was prevalent because the infrastructure did not exist for expert stroke evaluation in most hospitals, and imbalance in stroke severity between the treatment groups led to erroneous conclusions as to the validity of the data.

A second European trial (ECASS-II) studied the same t-PA dose $(0.9 \mathrm{mg} / \mathrm{kg})$ and completed in 1998 [51]. In contrast to the NINDS t-PA study, ECASS-II continued to study the 0 to $6-\mathrm{h}$ treatment window. Again, the majority of patients were treated in the 3- to 6-h time frame and no statistically significant difference was found between groups $(p=0.277)$. However, post-hoc analysis showed that using a slightly different cutoff of clinical efficacy revealed a treatment effect. Authors concluded that the observed trend of efficacy supported by the NINDS t-PA study results justifies thrombolysis in selected stroke patients within the 3-h time window. At the same time, a smaller study, the Alteplase Thrombolysis for Acute Noninterventional Therapy in Ischemic Stroke (ATLANTIS) study tested delayed (3- to 5-h) administration of alteplase, but it was negative. Independent re-analysis of the NINDS data [52], and a
Table 2 Inclusion and exclusion criteria for the NINDS t-PA stroke study

$\mathrm{BP}=$ blood pressure; $\mathrm{NIH}=$ National Institutes of Health; NINDS $=$ National Institute of Neurological Disorder and Stroke; $\mathrm{t}-\mathrm{PA}=$ tissue plasminogen activator

\begin{tabular}{|c|c|}
\hline Inclusion Criteria & Exclusion Criteria \\
\hline 1. Ischemic stroke with: & $\begin{array}{l}\text { 1. Stroke or serious head trauma withinthe previous } \\
3 \text { months }\end{array}$ \\
\hline a. Clearly defined onset time & 2. Major surgery within 14 days \\
\hline b. Measurable deficit on the NIH Stroke Scale & 3. History of intracranial hemorrhage \\
\hline \multirow[t]{11}{*}{$\begin{array}{l}\text { 2. Computed tomographic scan without } \\
\text { evidence of intracranial hemorrhage }\end{array}$} & $\begin{array}{l}\text { 4. BP of }>185 / 110 \text { or aggressive means to lower } \\
\text { the BP below this goal }\end{array}$ \\
\hline & 5. Rapidly improving or minor symptoms \\
\hline & 6. Symptoms suggestive of subarachnoid hemorrhage \\
\hline & $\begin{array}{l}\text { 7. Gastrointestinal or genitourinary hemorrhage within } \\
\text { the previous } 21 \text { days }\end{array}$ \\
\hline & $\begin{array}{l}\text { 8. Arterial puncture at a noncompressible site within } \\
7 \text { days }\end{array}$ \\
\hline & 9. Seizure at onset of the stroke \\
\hline & 10. Laboratory data \\
\hline & a. Glucose $>400$ or $<50 \mathrm{mg} / \mathrm{dL}$ \\
\hline & b. Prothrombin time $>15$ seconds \\
\hline & c. Platelet count $<100,000 \mathrm{~cm}^{3}$ \\
\hline & $\begin{array}{l}\text { d. Elevated partial-thromboplastin time in the setting } \\
\text { of receiving heparin within } 48 \text { hours. }\end{array}$ \\
\hline
\end{tabular}


pooled analysis of all patients in all of these 4 trials confirmed the positive effect of t-PA and demonstrated the importance of treating patients as early in the course of their infarction as possible [53]. The odds ratio of a favorable 3 -month outcome increased as the onset to treatment time decreased $(p=0.005)$. A statistically significant treatment effect was present between 3- and 4.5-h from onset (odds ratio, $1.4 ; 95$ confidence interval, 1.1-1.9), but the $95 \%$ confidence intervals crossed 1 in the 4.5- to 6-h time frame.

The apparent treatment effect between 3- and 4.5-h was formally tested in the phase III, randomized, double-blinded, placebo-controlled ECASS-III study [54]. A total of 821 patients were randomized with a median symptom onset to treatment time of $3 \mathrm{~h}$ and 59 minutes. The baseline median NIHSS score was 9 in the t-PA group and 10 in the placebo group. More patients had a favorable outcome with alteplase than with placebo $(52.4 \%$ vs $45.2 \%$; odds ratio, $1.34 ; 95 \%$ confidence interval, 1.02-1.76; $p=0.04)$. The incidence of symptomatic intracerebral hemorrhage (sICH) was higher with alteplase than with placebo $(2.4 \%$ vs. $0.2 \% ; p=0.008)$. Mortality did not differ significantly between the alteplase and placebo groups $(7.7 \%$ and $8.4 \%$, respectively; $p=0.68)$. A second pooled analysis that now included ECASS-III and a smaller Australian study, named Echoplanar Imaging Thrombolysis Evaluation (EPITHET), led to a position statement by the American Heart Association (AHA) and American Stroke Association (ASA), and a recommendation by the European Stroke Organization (ESO) endorsing the use of alteplase out to $4.5 \mathrm{~h}[55,56]$.

\section{Streptokinase for Ischemic Stroke}

Three large, randomized clinical trials of streptokinase have been completed. The Multicenter Acute Stroke Trial - Europe (MAST-E) was a double-blinded, randomized trial of the cardiac dose of streptokinase $v s$ placebo with a 6-h treatment window. MAST-E was terminated early by the data safety monitoring board after significantly higher rates of death (34\% vs 18\%) and symptomatic hemorrhage (21\% vs 3\%) occurred. Similar fates of early termination befell the Australian Streptokinase (ASK) trial and the Multicenter Acute Stroke Trial - Italy (MAST-I) trial due to increased hemorrhage and mortality $[32,57,58]$. Notably, in contrast to the development of ateplase for stroke, no dose-escalation safety studies were performed with streptokinase.

\section{Third Generation and Other Thrombolytics}

\section{Tenecteplase}

The three clinically relevant recombinant thrombolytic peptides are 1) alteplase (t-PA), 2) reteplase (r-PA), and 3) tenecteplase (TNK). The latter, TNK, is a structurally modified form of native t-PA (performed to increase its half-life and fibrin specificity), which has undergone preclinical and clinical study in ischemic stroke. Due to the modified structure, TNK has a longer half-life and can be delivered in a bolus with no infusion necessary. Already approved for myocardial infarction (MI), the drug also boasted an improved safety profile with lower systemic bleeding complications in MI [59]. In addition to the longer half-life, TNK is 14 times more fibrin specific and is more resistant to degradation from plasminogen activator-1 compared with rt-PA [60]. Theoretically, the greater specificity for fibrin explains the lower hemorrhage risk in the MI setting.

Embolic stroke models using rabbits have explored a headto-head comparison between rt-PA and TNK [61]. Chapman et al. [61] compared 4 groups of animals using radio-labeled injected blood clots: control (no lytic), rt-PA, low-dose TNK $(0.6 \mathrm{mg} / \mathrm{kg})$, and high-dose TNK $(1.5 \mathrm{mg} / \mathrm{kg})$. Both the rt-PA and the TNK animals verified thrombolysis resulting in the conclusion that both drugs lyse clots. Nevertheless, no statistically significant differences were found between rtPA and TNK in the rates of intracranial hemorrhage rates (66\% in rt-PA vs 55\% low-dose and 53\% high-dose TNK). The authors concluded that they could not demonstrate improved safety compared with rt-PA.

Clinical studies of TNK moved forward in 1999 when Haley et al. [62] performed a pilot, dose-escalation safety study in 88 stroke patients. All patients were treated within the 0 to 3 -h window using identical NINDS t-PA study inclusion/exclusion criteria. The follwing 4 dosage tiers were tested: $0.1,0.2,0.4$, and $0.5 \mathrm{mg} / \mathrm{kg}$ (maximum, $100 \mathrm{mg}$ ). A total of 25 patients were treated at each dose with the exception of the 0.5 tier that was stopped after 2 of 13 patients suffered sICH. No concurrent controls with alteplase were obtained, thus comparisons for clinical outcomes were purely historical. Authors concluded that TNK at doses of 0.1 to $0.4 \mathrm{mg} / \mathrm{kg}$ are safe in ischemic stroke, and a larger trial was designed. The next trial was funded by the National Institutes of Health and used a sophisticated design that allowed a seamless transition from phase II to III, provided a promising dose was found with adequate safety [63]. The trial began as a phase IIb randomized, double-blinded, and controlled trial that sought the optimal dose of tenecteplase: $0.1,0.25$, or $0.4 \mathrm{mg} / \mathrm{kg}$. The control arm was alteplase at standard dosing, and all patients were treated within the 0 to $3-\mathrm{h}$ window. By design, the study used a combination score that balanced sICH with early (24-h) neurological improvement and resulted in the dropping of the $0.4 \mathrm{mg} / \mathrm{kg}$ dose after only 73 patients had been enrolled. Three of 19 (15.8\%) highdose patients experienced sICH. The 2 lower doses were continued, but unfortunately, due to slow enrollment, the 
study was prematurely terminated. Investigators were unable to explore futility or treatment effects in the other arms with so few patients $(n=31)$. Despite the disappointing outcome of the study, authors mention that further study of tenecteplase may be warranted as an alternative treatment for acute ischemic stroke.

\section{Reteplase}

Relaptase (r-PA) demonstrated significantly higher rates of coronary recanalization in the RAPID trials compared with alteplase $(60 \%$ vs $45 \%$; $p<0.05)$, but has undergone only limited pre-clinical experimentation for cerebrovascular disease [64]. Yenari et al. [65] tested reteplase versus alteplase in a controlled study of 34 rabbits (embolic stroke model). Thrombolysis was performed 1-h after embolization of the internal carotid artery. Cerebral hemorrhage was not increased with r-PA and reperfusion was equally improved compared with rt-PA. Authors concluded that the advantage of single-bolus dosing of reteplase warranted further testing for stroke treatment. There are no further reported studies with IV reteplase monotherapy in the setting of acute ischemic stroke. However, small case-series have reported success with reteplase using an intra-arterial approach [66, 67].

\section{Desmoteplase}

Vampire bat (Desmodus rotundus) saliva contains a plasminogen activator that has a significantly greater amount of fibrin specificity compared to rt-PA. One of the known side-effects of rt-PA, neurotoxicity of adjacent parenchyma after blood-brain-barrier disruption (suggested in animal models to be related to glutamate receptor excitotoxicity), does not seem to be present in desmoteplasetreated models $[68,69]$.

The Desmoteplase In Acute Stroke (DIAS) study explored this new agent in stroke patients in an extended window [70]. Patients were treated between 3- and 9-h from symptom onset and were selected using magnetic resonance imaging (MRI) criteria that were believed to indicate evidence of salvageable tissue (diffusion/perfusion mismatch). A doubleblinded, placebo-controlled safety and dose-escalation study with 104 patients enrolled began by using a fixed-dosage design. However, after excessive sICH rates (26.7\%), it was changed to a weight-based scheme in 3 treatment arms: 1) $62.5 \mu \mathrm{g} / \mathrm{kg}$, 2) $90 \mu \mathrm{g} / \mathrm{kg}$, and 3) $125 \mu \mathrm{g} / \mathrm{kg}$. Only 1 of 57 desmoteplase-treated patients suffered a sICH (dosage $=$ $90 \mu \mathrm{g} / \mathrm{kg}$ ). Reperfusion rates captured with follow-up MRI verified the thrombolytic effects of the drug $(71.4 \%$ in the high-dose arm compared to $20 \%$ in the placebo). Reperfusion differs from recanalization, as the former reflects tissue perfusion to the area of potential infarction, whereas the latter relates to whether or not the parent vessel is reopened (regardless of the tissue bed downstream). There was a dosedependent increase in the rates of favorable clinical outcome: $13.3 \%, 46.7 \%$, and $60 \%$ of patients in the $62.5 \mu \mathrm{g} / \mathrm{kg}$, $90 \mu \mathrm{g} / \mathrm{kg}$, and $125 \mu \mathrm{g} / \mathrm{kg}$ desmoteplase groups, respectively, compared with $18.2 \%$ in the placebo group. The DIAS study produced promising results on 2 fronts: safety and efficacy of a new thrombolytic and imaging-selected thrombolysis in an extended time window.

The Dose Escalation of Desmoteplase for Acute Ischemic Stroke (DEDAS) study was an extension of the DIAS study that focused on the 2 most promising doses: $90 \mu \mathrm{g} / \mathrm{kg}$ and $125 \mu \mathrm{g} / \mathrm{kg}$. Again, DEDAS was a double-blinded, placebocontrolled safety and dose-escalation study (3- to 9-h from symptom onset) that was performed in 37 patients [71]. No sICH occurred. MRI reperfusion was most impressive with the $125 \mu \mathrm{g} / \mathrm{kg}$ dosage and correlated with good clinical outcome. Authors concluded that DIAS and DEDAS provided evidence that $125 \mu \mathrm{g} / \mathrm{kg}$ of desmoteplase is safe and effective for MRI stroke patients treated in an extended window.

DIAS-2 was the logical next step to the development of desmoteplase in acute ischemic stroke, which was a pivotal phase III clinical trial. DIAS-2 was a prospective, doubleblind, single-bolus study investigating the efficacy and safety of 2 doses of desmoteplase (90 and $125 \mu \mathrm{g} / \mathrm{kg}$ ), given as an IV bolus [72]. Patients were eligible for DIAS-2 if they could be treated within 3-to 9-h after the onset of stroke symptoms, if they had a score on the NIHSS of 4 to 20 , and if they had a distinct ischemic penumbra of at least $20 \%$ established by MRI (perfusion-weighted imaging/ diffusion-weighted imaging) or perfusion CT. Design of the study was predicated on enriching the population with patients that had penumbra (mismatch between dead tissue and tissue at risk). Therefore, these patients would be more likely to benefit from reperfusion. Assessment of mismatch was done by a visual estimate, and CT mismatch was performed by comparing cerebral blood flow with blood volume. The primary outcome was clinical improvement at day 90, defined as having achieved all of the following: an improvement in NIHSS score of 8 points or more (or an NIHSS score of $\leq 1$ ), a Barthel Index score of 75 to 100 , and a modified Rankin Scale score of 0 to 2 . DIAS-2 targeted an aggressive absolute treatment effect of $25 \%$. Between 2005 and 2007, 193 patients were randomized and 186 received treatment $(\mathrm{n}=57$ in $90 \mu \mathrm{g} / \mathrm{kg}$ arm; $\mathrm{n}=66$ in $125 \mu \mathrm{g} / \mathrm{kg}$, and $n=63$ placebo). Interestingly, only $30 \%$ of patients had a visible occlusion on baseline imaging. Unfortunately, despite adequate safety results (sICH rates of 3.5 and $4.5 \%$ in low- and high-dose arms, respectively) there was no signal of effect in the primary clinical outcome. Authors postulated a few different interpretations regarding 
the discrepant results between DIAS-2 and DEDAS/DIAS-1, such as: 1) milder strokes in DIAS-2 patients (median, $9 v s$ $11)$; 2) lower rates of thrombolysis in MIof 0 or 1 vessel occlusion (26\% vs 54\%); 3) use of CT-perfusion in DIAS-2, whereas MRI was the sole imaging modality used in prior studies; or 4) more patients with mild strokes in the placebo group of DIAS-2.

Post-hoc analysis revealed an $18 \%$ and $9 \%$ clinical response rate in patients with a thrombolysis in MI of 0 to 1 occlusion in the low- and high-dose arms, respectively. Response to treatment in this analysis has spurred the design of DIAS-3 and DIAS-4 studies (still ongoing), which only includes patients with occlusions $[73,74]$.

\section{Plasmin}

As described in earlier sections, plasmin is the final common pathway of traditional thrombolytics (so-called direct-acting fibrinolytic) and provides the enzymatic degradation of fibrin that results in clot lysis. Due to the short half-life and rapid inactivation (within seconds) of by $\alpha 2$-antiplasmin, plasmin is more suitable for local (intraarterial therapy) administration. In a rabbit model of thrombosed abdominal aorta, Marder et al. [75] found superior lysis with plasmin compared to t-PA and no rebleeding at puncture sites. Nine of 10 t-PA treated rabbits had re-bleeding at puncture sites.

Marder et al. [76] tested plasmin in a rabbit stroke model of thrombin-induced middle cerebral artery occlusion. Arterial recanalization (confirmed using angiography) was successful in all 9 rabbits infused with plasmin. Conversely, none of the 3 control rabbits recanalized spontaneously. Results were promising enough for the design of a phase I/IIa human study testing 3 doses of plasmin in middle cerebral artery stroke within $8.5 \mathrm{~h}$ of symptom onset [77].

\section{Ongoing Trials of IV Thrombolysis}

\section{Phase 3 Trials}

There are four major, ongoing clinical trials of $0.9 \mathrm{mg} / \mathrm{kg}$ dose alteplase (Table 3). All trials are phase 3 clinical efficacy trials that are predominantly attempting to extend the treatment window or explore treatment in different patient groups. Because there is limited information regarding efficacy and safety in stroke patients older than 80 years of age (and European authorities did not approve tPA for ages $>80$ ), both the Third International Stroke Trial (IST-3) and the Thrombolysis in Elderly Stroke Patients in Italy (TESPI) will enroll enough patients to address this important issue. Desmoteplase in Acute Stroke (DIAS-3) and (DIAS-4) is using the $90 \mu \mathrm{g} / \mathrm{kg}$ dosage of desmoteplase to test efficacy in image-selected patients. Extending the Time for Thrombolysis in Emergency Neurological Deficits (EXTEND) trial enrolls patients with neuroimaging evidence of penumbra. Although not an IV vs placebo trial, the Interventional Management of Stroke Trial-3 (IMS-3) is randomizing patients to standard $0.9 \mathrm{mg} / \mathrm{kg}$ IV t-PA $v s$ a bridging endovascular approach. Patients randomized to the interventional arm receive $0.6 \mathrm{mg} / \mathrm{kg}$ t-PA by IV followed by endovascular treatment that can deliver additional intraarterial lytic.

Table 3 Ongoing phase 3 clinical trials of intravenous thrombolysis $v s$ placebo

\begin{tabular}{|c|c|c|c|c|}
\hline Study Name & $\begin{array}{l}\text { Treatment Time } \\
\text { Window }\end{array}$ & $\begin{array}{l}\text { Planned Sample } \\
\text { Size }\end{array}$ & $\begin{array}{l}\text { Imaging Selection (Other } \\
\text { Than Noncontrast Head CT) }\end{array}$ & $\begin{array}{l}\text { Other Important Selection } \\
\text { Criteria }\end{array}$ \\
\hline $\begin{array}{l}\text { Third International Stroke } \\
\text { Trial (IST-3) }\end{array}$ & $0-6$ hours & 3,100 & None & $\begin{array}{l}\text { No upper-limit cutoff for age } \\
\text { or stroke severity }\end{array}$ \\
\hline $\begin{array}{l}\text { Extending the Time for } \\
\text { Thrombolysis in Emergency } \\
\text { Neurological Deficits (EXTEND) }\end{array}$ & $\begin{array}{l}\text { 3- to } 9-\mathrm{h} \text { (or } 4.5-\text { to } 9-\mathrm{h} \\
\text { according to local } \\
\text { guidelines) }\end{array}$ & 400 & $\begin{array}{l}\text { Penumbral imaging } \\
\text { required }\end{array}$ & $\begin{array}{l}\text { - NIHSS 4-26 with hemispheric } \\
\text { symptoms } \\
\text { - No upper-limit cutoff for age }\end{array}$ \\
\hline $\begin{array}{l}\text { Thrombolysis in Elderly Stroke } \\
\text { Patients in Italy (TESPI) }\end{array}$ & $0-3$ hours & 600 & None & $\begin{array}{l}\text { - Age }>80 \\
\text { - NIHSS }<17 \\
\text { - Any history of prior clinical } \\
\text { stroke and concomitant diabetes }\end{array}$ \\
\hline $\begin{array}{l}\text { Desmoteplase In Ascute Stroke } \\
\text { (DIAS-3) and (DIAS-4) }\end{array}$ & 3-9 hours & 320 & $\begin{array}{l}\text { MRA or CTA intracranial } \\
\text { occlusions (TIMI } 0 \text { or } 1 \text { ) }\end{array}$ & $\begin{array}{l}\cdot \text { Age } \leq 85 \\
\cdot \text { NIHSS 4-24 }\end{array}$ \\
\hline $\begin{array}{l}\text { Interventional Management } \\
\text { of Stroke Trial } 3 \text { (IMS-3) }\end{array}$ & $0-3$ hours & 900 & None & $\begin{array}{l}\text { - Large vessel occlusion or } \\
\text { NIHSS } \geq 10 \text {. } \\
\text { - Ages } 18-82\end{array}$ \\
\hline
\end{tabular}

$\mathrm{CT}=$ computed tomography $\mathrm{CTA}=$ computed tomographic angiography; NIHSS $=$ National Institutes of Health Stroke Scale; MRA $=$ magnetic resonance angiography; National Institutes of Health Stroke Scale; TIMI = thrombolysis in myocardial infarction 
Other Early Phase I and II Trials

Many phase I and phase II trials are ongoing, which test IV rt-PA combined with other therapeutic strategies. A few of these modalities include: anti-platelet agents (e.g., aspirin or glycoprotein IIb/IIIa inhibitors), anticoagulants (e.g., Argatroban manufacturer: GlaxoSmithKline, Philadelphia, PA), intra-arterial therapy, ultrasound-enhanced lysis (sonothrombolysis), hypothermia, and other neuroprotective medications or strategies (e.g., magnesium and albumin). Adjunctive rt-PA therapies offer a promising way to enhance the effects of rt-PA through many different pathophysiological pathways. Explorations of all these early phase studies are beyond the scope of this article.

\section{Conclusion}

IV thrombolysis remains the only proven medical treatment for reducing the disability caused by acute ischemic stroke. However, the time window of opportunity for treatment is still narrow as the majority of patients with ischemic stroke do not receive thrombolysis, and complete clot lysis occurs in the minority of patients [78]. Ongoing clinical trials aiming to improve rates of recanalization widen the treatment window or broaden eligibility so that more patients can benefit. Regardless of what new thrombolytic or adjunctive treatment, if any, is discovered to be effective for future stroke sufferers, it remains absolutely crucial that patients are transferred fast to stroke centers. In wellorganized stroke centers, it is possible to reach 20 minutes door to IV t-PA needle time [79].

Acknowledgment Full conflict of interest disclosure is available in the electronic supplementary material for this article.

This work was also supported by the Center for Clinical and Translational Sciences, which is funded by NIH Clinical and Translational Award UL1 RR024148 [TL1 RR024147 for the T32 program; KL2 RR0224149 for the K12 program] from the National Center for Research Resources. The content is solely the responsibility of the authors and does not necessarily represent the official views of the National Center for Research Resources or the NIH.

\section{References}

1. Mackay JMG. The atlas of heart disease and stroke. London: World Stroke Organization; 2004.

2. Asplund KSB, Peltonem M. From the twentieth to the twenty-first century: a public health perspective on stroke. In: Ginsberg MD, ed. Cerebrovascular Disease Pathophysiology, Diagnosis and Management. Malden, Mass: Blackwell Science; 1998.

3. Lloyd-Jones D, Adams RJ, Brown TM, et al. Heart disease and stroke statistics - 2010 update: a report from the American Heart Association. Circulation121:e46-e215.

4. Shattil SJ, Kashiwagi H, Pampori N. Integrin signaling: the platelet paradigm. Blood 1998;91:2645-2657.
5. Colman RW, Clowes AW, George JN, Goldhaber SZ, eds. Hemostasis and Thrombosis: Basic Principles and Clinical Practice. Philadelphia: Lippincott Williams \& Wilkins; 2006.

6. Loren M, Garcia Frade LJ, Torrado MC, Navarro JL. Thrombus age and tissue plasminogen activator mediated thrombolysis in rats. Thromb Res 1989;56:67-75.

7. Collen D. On the regulation and control of fibrinolysis. Edward Kowalski memorial lecture. Thromb Haemost 1980;43:77-89.

8. Tillett WS, Garner RL. The fibrinolytic activity of hemolytic streptococci. J Exp Med 1933;58:485-502.

9. Christensen LR, Macleod CM. A proteolytic enzyme of serum: characterization, activation, and reaction with inhibitors. J Gen Physiol 1945;28:559-583.

10. Johnson AJ, Tillett WS. The lysis in rabbits of intravascular blood clots by the streptococcal fibrinolytic system (streptokinase). J Exp Med 1952;95:449-464.

11. Fletcher AP, Alkjaersig N, Smyrniotis FE, Sherry S. The treatment of patients suffering from early myocardial infarction with massive and prolonged streptokinase therapy. Trans Assoc Am Physicians 1958;71:287-296.

12. Collen D. Molecular mechanisms of fibrinolysis and their application to fibrin-specific thrombolytic therapy. J Cell Biochem 1987;33:77-86.

13. Paciaroni M, Medeiros E, Bogousslavsky J. Desmoteplase. Expert Opin Biol Ther 2009;9:773-778.

14. Fletcher AP, Sherry S, Alkjaersig N, Smyrniotis FE, Jick S. The maintenance of a sustained thrombolytic state in man. Clinical observations on patients with myocardial infarction and other thromboembolic disorders. J Clin Invest 1959;38:1111-1119.

15. Schmutzler R, Heckner F, Kortge P, et al. Thrombolytic therapy of recent myocardial infarction. I. Introduction, plan of trial, general clinical results. Ger Med Mon 1966;11:308-314.

16. Bett JHN, Castaldi PA, Hale GS, et al. Australian multicentre trial of streptokinase in acute myocardial infarction. Lancet 1973;301:57-60.

17. Aber CP, Bass NM, Berry CL, et al. Streptokinase in acute myocardial infarction: a controlled multicentre study in the United Kingdom. Br Med J 1976;2:1100-1104.

18. Dioguardi N, Lotto A, Levi GF, et al. Controlled trial of streptokinase and heparin in acute myocardial infarction. Lancet 1971;2:891-895.

19. Streptokinase in acute myocardial infarction. European Cooperative Study Group for streptokinase treatment in acute myocardial infarction. N Engl J Med 1979;301:797-802.

20. Effectiveness of intravenous thrombolytic treatment in acute myocardial infarction. Gruppo italiano per lo studio della streptochinasi nell'infarto miocardico (GISSI). Lancet 1986;327:397-402.

21. GISSI-2: A factorial randomised trial of alteplase versus streptokinase and heparin versus no heparin among 12,490 patients with acute myocardial infarction. Gruppo italiano per lo studio della sopravvivenza nell'infarto miocardico. Lancet 1990;336:65-71.

22. ISIS-3: A randomised comparison of streptokinase vs tissue plasminogen activator vs anistreplase and of aspirin plus heparin vs aspirin alone among 41,299 cases of suspected acute myocardial infarction. ISIS-3 (third international study of infarct survival) collaborative group. Lancet 1992;339:753-770.

23. An international randomized trial comparing four thrombolytic strategies for acute myocardial infarction. The GUSTO investigators. N Engl J Med 1993;329:673-682.

24. Eagle KA, Guyton RA, Davidoff R, et al. ACC/AHA 2004 guideline update for coronary artery bypass graft surgery: summary article. A report of the American College of Cardiology/American Heart Association task force on practice guidelines (committee to update the 1999 guidelines for coronary artery bypass graft surgery). J Am Coll Cardiol 2004;44:e213-e310 
25. Sussman BJ, Fitch TS. Thrombolysis with fibrinolysin in cerebral arterial occlusion. J Am Med Assoc 1958;167:1705-1709.

26. Meyer JS, Gilroy J, Barnhart MI, Johnson JF. Therapeutic thrombolysis in cerebral thromboembolism. Double-blind evaluation of intravenous plasmin therapy in carotid and middle cerebral arterial occlusion. Neurology 1963;13:927-937.

27. Meyer JS, Gilroy J, Barnhart MI, Johnson JF. Anticoagulants plus streptokinase therapy in progressive stroke. JAMA 1964;189:373.

28. Fletcher AP, Alkjaersig N, Lewis M, et al. A pilot study of urokinase therapy in cerebral infarction. Stroke 1976;7:135-142.

29. del Zoppo GJ, Ferbert A, Otis S, et al. Local intra-arterial fibrinolytic therapy in acute carotid territory stroke. A pilot study. Stroke 1988;19:307-313.

30. Hacke W, Zeumer H, Ferbert A, Bruckmann H, del Zoppo GJ. Intra-arterial thrombolytic therapy improves outcome in patients with acute vertebrobasilar occlusive disease. Stroke 1988; 19:1216-1222.

31. Thrombolytic therapy in thrombosis: A National Institutes of Health Consensus Development Conference. Ann Intern Med 1980;93:141-144.

32. Thrombolytic therapy with streptokinase in acute ischemic stroke. The multicenter acute stroke trial — Europe study group. N Engl J Med 1996;335:145-150.

33. Crowell RM, Marcoux FW, DeGirolami U. Variability and reversibility of focal cerebral ischemia in unanesthetized monkeys. Neurology 1981;31:1295-1302.

34. Zeumer $\mathrm{H}$. Vascular recanalizing techniques in interventional neuroradiology. J Neurol 1985;231:287-294.

35. Mori $\mathrm{E}$, Yoneda $\mathrm{Y}$, Tabuchi $\mathrm{M}$, et al. Intravenous recombinant tissue plasminogen activator in acute carotid artery territory stroke. Neurology 1992;42:976-982.

36. del Zoppo GJ, Zeumer H, Harker LA. Thrombolytic therapy in stroke: possibilities and hazards. Stroke 1986;17:595-607.

37. Zivin JA, Fisher M, DeGirolami U, Hemenway CC, Stashak JA. Tissue plasminogen activator reduces neurological damage after cerebral embolism. Science 1985;230:1289-1292.

38. Lyden PD, Madden KP, Clark WM, Sasse KC, Zivin JA. Incidence of cerebral hemorrhage after treatment with tissue plasminogen activator or streptokinase following embolic stroke in rabbits [corrected]. Stroke 1990;21:1589-1593.

39. Brott TG, Haley EC Jr., Levy DE, et al. Urgent therapy for stroke. Part I. Pilot study of tissue plasminogen activator administered within 90 minutes. Stroke 1992;23:632-640.

40. Haley EC Jr., Levy DE, Brott TG, et al. Urgent therapy for stroke. Part II. Pilot study of tissue plasminogen activator administered 91-180 minutes from onset. Stroke 1992;23:641-645.

41. von Kummer R, Hacke W. Safety and efficacy of intravenous tissue plasminogen activator and heparin in acute middle cerebral artery stroke. Stroke 1992;23:646-652.

42. del Zoppo GJ, Poeck K, Pessin MS, et al. Recombinant tissue plasminogen activator in acute thrombotic and embolic stroke. Ann Neurol 992;32:78-86.

43. Hacke W, Kaste M, Fieschi C, et al. Intravenous thrombolysis with recombinant tissue plasminogen activator for acute hemispheric stroke. The European Cooperative Acute Stroke Study (ECASS). JAMA 1995;274:1017-1025.

44. Tissue plasminogen activator for acute ischemic stroke. The National Institute of Neurological Disorders and Stroke rt-PA Stroke Study Group. N Engl J Med 1995;333:1581-1587.

45. Grotta JC, Alexandrov AV. tPA-associated reperfusion after acute stroke demonstrated by spect. Stroke 1998;29:429-432.

46. Generalized efficacy of t-PA for acute stroke. Subgroup analysis of the NIND t-PA stroke trial. Stroke 1997;28:2119-2125.

47. Intracerebral hemorrhage after intravenous t-PA therapy for ischemic stroke. The NINDS t-PA Stroke Study Group. Stroke 1997;28:2109-2118.
48. Kwiatkowski TG, Libman RB, Frankel M, et al. Effects of tissue plasminogen activator for acute ischemic stroke at one year. National Institute of Neurological Disorders And Stroke Recombinant Tissue Plasminogen Activator Stroke Study Group. N Engl J Med 1999;340:1781-1787.

49. Marler JR, Tilley BC, Lu M, et al. Early stroke treatment associated with better outcome: The NINDS rt-PA stroke study. Neurology 2000;55:1649-1655.

50. Saver JL. Number needed to treat estimates incorporating effects over the entire range of clinical outcomes: novel derivation method and application to thrombolytic therapy for acute stroke. Arch Neurol 2004;61:1066-1070.

51. Hacke W, Kaste M, Fieschi C, et al. Randomised double-blind placebo-controlled trial of thrombolytic therapy with intravenous alteplase in acute ischaemic stroke (ECASS II). Second European-Australasian Acute Stroke Study Investigators. Lancet 1998;352:1245-1251.

52. Ingall TJ, O'Fallon WM, Asplund $\mathrm{K}$, et al. Findings from the reanalysis of the NINDS tissue plasminogen activator for acute ischemic stroke treatment trial. Stroke 2004;35:2418-2424.

53. Hacke W, Donnan G, Fieschi C, et al. Association of outcome with early stroke treatment: Pooled analysis of ATLANTIS, ECASS, and NINDS rt-PA stroke trials. Lancet 2004;363:768-774.

54. Hacke W, Kaste M, Bluhmki E, et al. Thrombolysis with alteplase 3 to 4.5 hours after acute ischemic stroke. N Engl J Med 2008;359:1317-1329.

55. del Zoppo GJ, Saver JL, Jauch EC, Adams HP Jr. Expansion of the time window for treatment of acute ischemic stroke with intravenous tissue plasminogen activator: a science advisory from the American Heart Association/American Stroke Association. Stroke 2009;40:2945-2948.

56. Lees KR, Bluhmki E, von Kummer R, et al. Time to treatment with intravenous alteplase and outcome in stroke: An updated pooled analysis of ECASS, ATLANTIS, NINDS, and EPITHET trials. Lancet 2010;375:1695-1703.

57. Randomised controlled trial of streptokinase, aspirin, and combination of both in treatment of acute ischaemic stroke. Multicentre acute stroke trial-italy (MAST-I) group. Lancet 1995;346:1509-1514.

58. Donnan GA, Davis SM, Chambers BR, et al. Streptokinase for acute ischemic stroke with relationship to time of administration: Australian streptokinase (ASK) trial study group. JAMA 1996;276:961-966.

59. Van De Werf F, Adgey J, Ardissino D, et al. Single-bolus tenecteplase compared with front-loaded alteplase in acute myocardial infarction: The ASSENT-2 double-blind randomised trial. Lancet 1999;354:716-722.

60. Thomas GR, Thibodeaux H, Errett CJ, et al. A long-half-life and fibrin-specific form of tissue plasminogen activator in rabbit models of embolic stroke and peripheral bleeding. Stroke 1994;25:2072-2079.

61. Chapman DF, Lyden P, Lapchak PA, Nunez S, Thibodeaux H, Zivin J. Comparison of TBK with wild-type tissue plasminogen activator in a rabbit embolic stroke model. Stroke 2001;32:748-752.

62. Haley EC Jr., Lyden PD, Johnston KC, Hemmen TM. A pilot dose-escalation safety study of tenecteplase in acute ischemic stroke. Stroke 2005;36:607-612.

63. Haley EC Jr., Thompson JL, Grotta JC, et al. Phase IIb/III trial of tenecteplase in acute ischemic stroke: results of a prematurely terminated randomized clinical trial. Stroke 41:707-711.

64. Weaver WD. Results of the RAPID 1 and RAPID 2 thrombolytic trials in acute myocardial infarction. Eur Heart J1996;17(suppl E):14-20.

65. Yenari MA, Lee LK, Beaulieu C, et al. Thrombolysis with reteplase, an unglycosylated plasminogen activator variant, in experimental embolic stroke. J Stroke Cerebrovasc Dis 1998;7:179-186. 
66. Qureshi AI, Ali Z, Suri MF, et al. Intra-arterial third-generation recombinant tissue plasminogen activator (reteplase) for acute ischemic stroke. Neurosurgery 2001;49:41-50.

67. Sugg RM, Noser EA, Shaltoni HM, et al. Intra-arterial reteplase compared to urokinase for thrombolytic recanalization in acute ischemic stroke. AJNR Am J Neuroradiol 2006;27:769-773.

68. Liberatore GT, Samson A, Bladin C, Schleuning WD, Medcalf RL. Vampire bat salivary plasminogen activator (desmoteplase): a unique fibrinolytic enzyme that does not promote neurodegeneration. Stroke 2003;34:537-543.

69. Reddrop C, Moldrich RX, Beart PM, et al. Vampire bat salivary plasminogen activator (desmoteplase) inhibits tissue-type plasminogen activator-induced potentiation of excitotoxic injury. Stroke 2005;36:1241-1246.

70. Hacke W, Albers G, Al-Rawi Y, et al. The desmoteplase in acute ischemic stroke trial (DIAS): A phase II MRI-based 9-hour window acute stroke thrombolysis trial with intravenous desmoteplase. Stroke 2005;36:66-73.

71. Furlan AJ, Eyding D, Albers GW, et al. Dose escalation of desmoteplase for acute ischemic stroke (DEDAS): evidence of safety and efficacy 3 to 9 hours after stroke onset. Stroke 2006;37:1227-1231.

72. Hacke W, Furlan AJ, Al-Rawi Y, et al. Intravenous desmoteplase in patients with acute ischaemic stroke selected by MRI perfusiondiffusion weighted imaging or perfusion CT (DIAS-2): A prospective, randomised, double-blind, placebo-controlled study. Lancet Neurol 2009;8:141-150.
73. H. Lundbeck A/S. Efficacy and safety study of desmoteplase to treat acute ischemic stroke (DIAS-3). In: ClinicalTrials.gov [Internet]. Bethesda (MD): National Library of Medicine (US). Available at: http://clinicaltrials.gov/show/NCT00790920 NLM Identifier: NCT00790920. Accessed: November 14, 2010.

74. Lundbeck H A/S. Efficacy and safety study of desmoteplase to treat acute ischemic stroke (DIAS-4). In: ClinicalTrials.gov [Internet]. Bethesda (MD): National Library of Medicine (US). Available at: http://clinicaltrials.gov/show/NCT00856661 NLM Identifier: NCT00856661. Accessed: November 14, 2010.

75. Marder VJ, Landskroner K, Novokhatny V, et al. Plasmin induces local thrombolysis without causing hemorrhage: a comparison with tissue plasminogen activator in the rabbit. Thromb Haemost 2001;86:739-745.

76. Marder VJ, Jahan R, Gruber T, Goyal A, Arora V. Thrombolysis with plasmin: Implications for stroke treatment. Stroke 2010;41:S45-S49.

77. Talecris Biotherapeutics. A safety and dose finding study of plasmin (human) administered into the middle cerebral artery of stroke patients. In: ClinicalTrials.gov [Internet]. Bethesda (MD): National Library of Medicine (US). Available at: http://clinicaltrials.gov/show/ NCT01014975 NLM Identifier: NCT01014975. Accessed: November 14, 2010.

78. Alexandrov AV, Grotta JC. Arterial reocclusion in stroke patients treated with intravenous tissue plasminogen activator. Neurology 2002;59:862-867.

79. Mustanoja S, Meretoja A, Putaala J, et al. Outcome by stroke etiology in patients receiving thrombolytic treatment: Descriptive subtype analysis. Stroke 2011;42:102-106. 